\title{
Distinct patterns of Internet and smartphone-related problems among adolescents by gender: Latent class analysis
}

 \\ YONG-SIL KWEON $^{1 *}$, YOUNGJO LEE ${ }^{5}$, DAI JIN KIM ${ }^{6}$ and JUNG-SEOK $\mathrm{CHOI}^{3,7 *}$
${ }^{1}$ Department of Psychiatry, College of Medicine, Uijeongbu St. Mary’s Hospital, The Catholic University of Korea, Seoul, Republic of Korea
${ }^{2}$ Department of Statistics, Ewha Womans University, Seoul, Republic of Korea
${ }^{3}$ Department of Psychiatry, SMG-SNU Boramae Medical Center, Seoul, Republic of Korea
${ }^{4}$ I Will Center, Seoul Metropolitan Boramae Youth Center, Seoul, Republic of Korea
${ }^{5}$ Department of Statistics, Seoul National University, Seoul, Republic of Korea
${ }^{6}$ Department of Psychiatry, College of Medicine, Seoul St. Mary's Hospital, The Catholic University of Korea, Seoul, Republic of Korea
${ }^{7}$ Department of Psychiatry and Behavioral Science, College of Medicine, Seoul National University, Seoul, Republic of Korea

(Received: August 21, 2017; revised manuscript received: March 9, 2018; accepted: March 24, 2018)

\begin{abstract}
Background and objectives: The ubiquitous Internet connections by smartphones weakened the traditional boundaries between computers and mobile phones. We sought to explore whether smartphone-related problems differ from those of computer use according to gender using latent class analysis (LCA). Methods: After informed consents, 555 Korean middle-school students completed surveys on gaming, Internet use, and smartphone usage patterns. They also completed various psychosocial instruments. LCA was performed for the whole group and by gender. In addition to ANOVA and $\chi^{2}$ tests, post-hoc tests were conducted to examine differences among the LCA subgroups. Results: In the whole group $(n=555)$, four subtypes were identified: dual-problem users $(49.5 \%)$, problematic Internet users (7.7\%), problematic smartphone users (32.1\%), and "healthy" users (10.6\%). Dual-problem users scored highest for addictive behaviors and other psychopathologies. The gender-stratified LCA revealed three subtypes for each gender. With dual-problem and healthy subgroup as common, problematic Internet subgroup was classified in the males, whereas problematic smartphone subgroup was classified in the females in the gender-stratified LCA. Thus, distinct patterns were observed according to gender with higher proportion of dual-problem present in males. While gaming was associated with problematic Internet use in males, aggression and impulsivity demonstrated associations with problematic smartphone use in females. Conclusions: An increase in the number of digital media-related problems was associated with worse outcomes in various psychosocial scales. Gaming may play a crucial role in males solely displaying Internet-related problems. The heightened impulsivity and aggression seen in our female problematic smartphone users requires further research.
\end{abstract}

Keywords: Internet, smartphone, addiction, latent class analysis, gender, game

\section{INTRODUCTION}

Information technologies and wireless communications have brought rapid changes in everyday life. Communication, education, entertainment, and commercial transactions are increasingly taking place online. In Europe, household Internet access rose from $55 \%$ in 2007 to $85 \%$ in 2015 , and Internet access through a mobile device also increased from $36 \%$ in 2012 to 59\% in 2016 (Eurostat, 2017). Personal computers and smartphones have also become popular among children and adolescents. Indeed, even mentioning the increased use by adolescents appears as a cliché in the current climate.

Despite effecting many convenient and positive changes in education and recreation, excessive or inappropriate use of the new digital media by children and adolescents has heightened the concerns of parents and the wider community, including schools, with respect to potential disruption of normal development and academic achievement, and exposure to inappropriate content, such as pornography. The negative consequences of the new digital media on physical health may range from obesity to even death by accident, with the greatest danger associated with smartphones posed by use while crossing the road, as

\footnotetext{
* Corresponding authors: Jung-Seok Choi, MD, PhD; Department of Psychiatry, SMG-SNU Boramae Medical Center, 20, Boramae-ro 5-gil, Dongjak-gu, Seoul 07061, Republic of Korea; Phone: +82 2870 3461; Fax: +82 2831 2826; E-mail: choijs73@gmail.com; Yong-Sil Kweon, MD, PhD; Department of Psychiatry, College of Medicine, Uijeongbu St. Mary's Hospital, The Catholic University of Korea, 222 Banpo-daero, Seocho-gu, Seoul 06591, Republic of Korea; Phone: +82 31820 3032; Fax: +82 31847 3630; E-mail: yskwn@catholic.ac.kr
}

This is an open-access article distributed under the terms of the Creative Commons Attribution-NonCommercial 4.0 International License, which permits unrestricted use, distribution, and reproduction in any medium for non-commercial purposes, provided the original author and source are credited, a link to the CC License is provided, and changes - if any - are indicated. 
reported for younger age groups (Ayers et al., 2016; Hull, Draghici, \& Sargent, 2012; Lennon, Oviedo-Trespalacios, \& Matthews, 2017; Vandewater, Shim, \& Caplovitz, 2004). Prior research has indicated that such misuse may also negatively impact mental health, by increasing sleep disturbance, depression, anxiety, impulsivity, and even suicidality (Achab et al., 2011; Gentile et al., 2011; Kim et al., 2006; Messias, Castro, Saini, Usman, \& Peeples, 2011; Wei, Chen, Huang, \& Bai, 2012; Weinstein \& Weizman, 2012; Wu, Tao, Zhang, Zhang, \& Tao, 2015).

During their youth, today's parents may have used computers or conventional mobile phones, but were not exposed to the high-speed Internet connections and smartphones that their offspring use. Thus, they may experience difficulties in recognizing a problematic use or features associated with it. Although concerned, parents and the wider community could be confused by these new electronic media phenomena and may also experience difficulties in guiding their children in their use.

As per the famous old saying of "time will tell," longitudinal studies and the passage of time will provide clarity regarding the consequences of new media usage, especially for highly excessive patterns of use. To achieve this, adequate classification of the problem is essential. However, it is also uncertain whether the problems related to smartphones are distinct from the Internet-related problems associated with the computer use. Most previous studies were concerned either with smartphones or computers but not both, despite this uncertainty. In addition to the device-related factors, individual characteristics may also influence the usage patterns. Thus, any exploration of these relatively new phenomena faces many challenges.

Latent class analysis (LCA) may represent a valuable tool, because it requires no structural modeling. Rather than relying on fixed assignments, LCA derives a set of latent variables from a series of observed variables and allocates them to a latent class. Thus, this analytical method may be particularly useful in revealing patterns of use of new digital media and, in turn, for adequate classification by usage pattern. A few studies used LCA as a statistical method to explore potential gaming (Borsari et al., 2013; Carras et al., 2017; Kiraly et al., 2017; Lemmens, Valkenburg, \& Gentile, 2015), Internet addiction (Rumpf et al., 2014), and social network service-using subgroups (Dantlgraber, Wetzel, Schutzenberger, Stieger, \& Reips, 2016). However, only one study, which was conducted by some of the present authors, simultaneously analyzed both Internet- and smartphone-related problems (Mok et al., 2014).

In the previous study, Internet and smartphone usage patterns were found to differ by gender among university students. Three distinct Internet and smartphone user groups were identified for each gender. Males were classified into similar low, moderate, and high addiction groups for both Internet and smartphone use. However, females showed different usage patterns. While two female subgroups displayed low and high levels of addiction to both Internet and smartphone usage, the remaining subgroup demonstrated low addiction to the Internet but high addiction to smartphones, rather than simply a moderate level of addiction to both.
Thus, the previous study first revealed a different pattern of addictive use of the Internet and/or smartphones by gender according to LCA (Mok et al., 2014). Although the demonstration of such a gender difference made a meaningful contribution to the literature, there was also a major limitation; specifically, no plausible explanation was provided for the gender difference.

To overcome the shortcomings of prior studies, we explored Internet and smartphone usage patterns in a larger sample, and captured more detailed information on digital media use and a broader range of psychosocial variables that are known to be associated with problematic use, such as depression, anxiety, attention-deficit hyperactivity disorder (ADHD), aggression, and impulsivity. Considering the fact that the fronto-striatal mismatch in neurodevelopment of the juvenile brains renders the adolescents to increased impulsivity (Galvan, Hare, Voss, Glover, \& Casey, 2007), this study employed a range of instruments that measure various aspects of dysregulated cognitive control or reward-seeking. It was postulated that such comprehensive assessment of multiple domains may better reveal of which psychosocial characteristics are more related to excessive use pattern of the Internet or smartphones. Moreover, no study has examined patterns of addictive use of the Internet and/or smartphones by gender in adolescents using LCA. Thus, the primary objective of this study was to examine, in a relatively large sample, whether the previously demonstrated gender differences in electronic media usage also applied to adolescents. Second, we sought to identify psychosocial and media-related factors contributing to such gender differences in adolescents.

\section{METHODS}

\section{Participants}

In total, 714 students from five public middle schools in Seoul, Republic of Korea participated in this study. Different school years may act as confounders due to differences in developmental stage or culture. Therefore, we recruited all the participants from same school year of year 9 to ensure the homogeneity of our sample. The participating students completed the questionnaires at their own school and gift vouchers were provided as a reward for participation. We excluded 159 samples due to missing values on either the Internet or Smartphone Addiction Scales (SASs). Consequently, 555 students (295 males and 260 females) were included in the final analysis.

\section{Measures}

Internet Addiction Test (IAT). The IAT is a 20 -item scale, developed by Young to assess the severity of addiction to the Internet. Each item is rated on a 5-point scale from ranging 1 (very rarely) to 5 (very frequently). Total scores on the instrument can range from 20 to 100, with a higher total scores indicating more severe Internet addiction (Young, 1999). The overall Cronbach's $\alpha$ coefficient was .889 in a meta-analysis (Frangos, Frangos, \& Sotiropoulos, 2012). 
Smartphone Addiction Scale (SAS). The SAS consists of 33 items that evaluate problematic smartphone use across six domains: daily-life disturbance, positive anticipation, withdrawal, cyberspace-oriented relationship, overuse, and tolerance. Each item is rated on a 6-point scale ranging from 1 (strongly disagree) to 6 (strongly agree). A higher total SAS score indicates more severe smartphone addiction (Kwon et al., 2013). It previously demonstrated a good internal consistency with the Cronbach's $\alpha$ coefficient of .967 (Kwon et al., 2013).

Behavioral Inhibition System/Behavioral Activation System Scales (BIS/BAS). The BIS and BAS Scales were developed based on Gray's biopsychological theory of personality to assess sensitivity to punishment and rewards, respectively (Carver \& White, 1994; Gray, 1990). Altogether, they consist of 20 items, which are rated on 4-point scales ranging from 1 (very true for me) to 4 (very false for me). The BIS contains seven items that measure attitudes toward potentially unpleasant stimuli/anticipated punishments. The BAS consists of 13 items that measure the degree of motivation for rewards/goals/pleasure, which can further be subdivided into three subscales: reward responsiveness (BAS-R), drive to pursue goals (BAS-D), and funseeking (BAS-F; Carver \& White, 1994). The Cronbach's $\alpha$ coefficient for BIS was .74, while the coefficient values for BAS-R, BAS-D, and BAS-F were .73, .76, and .66, respectively (Carver \& White, 1994).

Beck Depression Inventory (BDI). The BDI is a 21-item self-rated questionnaire assessing the severity of depressive symptoms experienced in the past week on a 4-point scale (Beck, Ward, Mendelson, Mock, \& Erbaugh, 1961). The validated Korean version was used, which showed the Cronbach's $\alpha$ coefficient of .85 (Rhee et al., 1995).

Beck Anxiety Inventory (BAI). The BAI is a 21 -item selfrated questionnaire assessing the severity of anxiety symptoms experienced during the past week on a 4-point scale (Beck, Epstein, Brown, \& Steer, 1988). In Korean validation, it displayed a good internal consistency with the Cronbach's $\alpha$ coefficient of .93 (Kim et al., 2016).

Conners-Wells' Adolescent Self-Report Scale - short version (CASS-S). The CASS-S consists of 27 items that assess ADHD symptoms, focusing on cognitive, hyperactivityrelated, and conduct problems in adolescents based on a 4-point scale ranging from 0 (not true) to 3 (very often) (Conners, 1997). The CASS-S demonstrated good internal consistency with the Cronbach's $\alpha$ coefficient of .88 (Bahn, Shin, Cho, \& Hong, 2001).

Barratt Impulsiveness Scale (BIS-11). The BIS-11 is a 30 -item self-report questionnaire that assesses impulsivity. Originally developed in 1959, it is currently in its 11th iteration. It assesses three facets of impulsivity - attentional, motor, and non-planning - which are also measured by the Korean version (Lee et al., 2012; Patton, Stanford, \& Barratt, 1995). The BIS-11 displayed a fair internal consistency with the Cronbach's $\alpha$ coefficient ranging from .79 to .83 (Patton et al., 1995).

Aggression Questionnaires (AQs). The AQ consists of 29 items that assess physical aggression, verbal aggression, hostile aggression, and anger. Each item is rated on a 5-point scale ranging from 1 (uncharacteristic of me) to 5 (very characteristic of me) (Buss \& Perry, 1992). The AQ showed a good internal consistency with the Cronbach's $\alpha$ coefficient of .889 (Buss \& Perry, 1992).

Anger Expression Scale $(A X)$. The $\mathrm{AX}$ is a 24 -item scale with eight questions each on anger-in, anger-out, and angercontrol (Spielberger et al., 1985). It measures the frequency of anger experience and expression, and has been validated for use in Korean populations with Cronbach's $\alpha$ coefficient ranging from .73 to .81 (Hahn, Lee, \& Chon, 1998).

Internet/smartphone usage patterns survey. We also investigated specific patterns of Internet usage. First, the adolescents indicated the age at which they started using the Internet, the nature of their Internet use, including games and other activities (e.g., social networking sites, messenger, and web surfing), and daily amount of Internet use on weekdays and weekends. They also indicated their reasons for using the Internet. We also determined the daily amount of time spent using smartphones on weekdays and weekends.

\section{Data analyses}

Data analyses were performed according to the following four steps: (a) descriptive statistics were generated to examine the overall distributions of the variables; (b) independent $t$-tests were performed to identify gender differences with regard to Internet and smartphone addiction; (c) LCA was used for classifying the subgroups (i.e., latent classes) based on the extent of Internet and smartphone addiction, for both males and females; and (d) analysis of variance (ANOVA) and $\chi^{2}$ tests were carried out to examine difference in variables, such as personality, clinical features, and usage patterns among the subgroups.

LCA is a statistical method to identify homogeneous classes, where the homogeneity may not be observed directly, but instead through latent variables derived from a series of observed variables (Hagenaars \& McCutcheon, 2002). Because LCA assesses the probability of a given case belonging to a particular latent class, instead of making a prior assignment to a model, the method could be particularly useful for classifying new phenomena without potentially subjective biases from modeling, and may overcome the shortcomings associated with cluster analysis. In this study, we used logtransformed data in LCA for the normal approximation.

To determine the best-fitting LCA model, the following objectives of statistical indices were considered: the Bayesian information criterion (BIC), Akaike information criterion (AIC), and the Bootstrap Likelihood Ratio Test (BLRT). The BIC and AIC are descriptive indices of the fitness of the LCA model, with lower values indicating a better fit. The BLRT statistically tests whether the current model ( $n$ classes) is better than the former model ( $n-1$ classes). When the current model significantly fits better than the former model, the BLRT also yields a significant $p$ value (Nylund, Asparouhov, \& Muthén, 2007).

After determining the best-fitting model with the optimal number of classes, according to these reliable and widely used indices, cross-class comparisons were performed. Psychosocial and digital media-related variables, such as IAT and SAS scores, and electronic media usage survey data were compared among the latent classes. These interclass comparisons were carried out using ANOVA and $\chi^{2}$ tests for continuous and categorical values, respectively. When 
significant differences were found, post-hoc tests were performed using Tukey's honest significant difference tests. The R software package was used for all statistical procedures (R Development Core Team, 2011). All analyses were conducted taking $p<.05$ as the level of significance.

\section{Ethics}

All subjects received an explanation about the research and provided written informed consent prior to participation. The study was approved by the Institutional Review Board of Seoul St. Mary's Hospital, Seoul, Republic of Korea (KC15EISI0103) and was conducted in accordance with the Declaration of Helsinki.

\section{RESULTS}

For the LCA of all students $(N=555)$, a four-class model was determined as the best-fitting model according to the estimated BIC (Table 1).

The four classes were as follows: (a) dual-problem group, demonstrating high severity for both Internet- and smartphone-related problems; (b) problematic Internet group, displaying high severity for Internet-related problems but low severity for smartphone-related problems; (c) problematic smartphone group, showing low severity for Internetrelated problems but high severity for smartphone-related problems; and (d) a "healthy" group scoring low for both Internet- and smartphone-related problems (Figure 1).

Post-hoc interclass comparisons revealed that the dualproblematic group was more likely to score higher on the Internet and smartphone problem questionnaires, as well as worse psychosocial outcomes in general (Table 2).

The dual-problem group significantly demonstrated higher scores than the problematic Internet user group on the IAT (42.8 vs. 35.8, $p<.001)$, SAS (92.6 vs. 46.5, $p<.001)$, BIS (17.8 vs. $15.6, p=.002)$, BAS-F (9.0 vs. 7.7, $p=.041)$, BDI (8.9 vs. 2.8, $p<.001)$, BAI (8.9 vs. 2.7 , $p<.001)$, BIS-11 (65.8 vs. $61.5, p=.005)$, CASS-S (21.7 vs. $14.3, p=.002)$, AQ (70.4 vs. $52.4, p<.001)$, and AX (56.2 vs. 49.5, $p=.002)$. However, there was no significant difference in the average number of hours spent gaming in one session, or the average number of hours spent gaming at the weekend, between the dual-problem group and the problematic Internet group.

The dual-problem group also significantly showed higher scores than the problematic smartphone group on the IAT

Table 1. Indicators of fit for models in the whole subjects $(N=555)$

\begin{tabular}{lccc}
\hline Model & BIC & AIC & BLRT $p$ value \\
\hline Two classes & 614.6392 & 571.4495 & .001 \\
Three classes & 583.8394 & 519.0549 & .001 \\
Four classes & $\mathbf{5 8 3 . 1 7 4 4}$ & 496.7950 & .001 \\
Five classes & 607.9873 & 500.0131 & .390 \\
\hline
\end{tabular}

Note. Bold value represents the lowest BIC value and signifies that the model composed by four class is most fit. AIC: Akaike information criterion; BIC: Bayesian information criterion; BLRT: Bootstrap Likelihood Ratio Test.



Figure 1. Latent class analysis of the whole subjects. SAS: Smartphone Addiction Scale; IAT: Internet Addiction Test

(42.8 vs. $23.8, p<.001)$, SAS (92.6 vs. $80.7, p<.001)$, BAS (30.1 vs. 27.5, $p=.013)$, BAS-D (8.9 vs. 8.1, $p=.019)$, BAS-F (9.0 vs. 7.8, $p<.001)$, BAI (8.9 vs. $5.0, p<.001)$, BIS-11 (65.8 vs. 62.7, $p<.001)$, CASS-S (21.7 vs. $15.1, p<.001)$, AQ (70.4 vs. $60.1, p<.001)$, and $\mathrm{AX}(56.2$ vs. $51.8, p<.001)$. In addition, the average hours spent gaming $(1.8$ vs. $0.9 \mathrm{hr}, p<.001)$, average daily gaming hours on weekday $(1.3 \mathrm{vs} .0 .6 \mathrm{hr}, p<.001)$ and weekend $(2.5$ vs. $1.1 \mathrm{hr}, p<.001)$, hours of daily non-gaming Internet usage on weekdays (1.3 vs. $1.0 \mathrm{hr}$, $p=.017)$, preference for Internet cafés as a gaming venue ( 0.2 vs. $0.1, p=.013)$, and positive response rate to the use of the Internet whenever possible (0.2 vs. $0.1, p=.010)$ were significantly greater in the dual group than the problematic smartphone group. However, the dual-problem and the problematic smartphone groups showed no statistical difference in BIS, BAS-R, or BDI scores, or in the number of hours of non-gaming Internet use or use of smartphone whenever possible in the post-hoc analysis.

The problematic Internet group played games for significantly longer time than the dual-problem group on average on weekdays ( 2.0 vs. $1.3 \mathrm{hr}, p=.010)$. When compared with the problematic smartphone user group, the problematic Internet user group had significantly higher IAT scores (35.8 vs. 23.8, $p<.001)$, a higher average number of hours spent gaming in one session ( 2.3 vs. $0.9 \mathrm{hr}, p<.001)$, and a higher average number of hours spent gaming on weekdays ( $2.0 \mathrm{vs}$. $0.6 \mathrm{hr}$, $p<.001)$ and at the weekends (3.1 vs. $1.1 \mathrm{hr}, p<.001)$.

On the contrary, the problematic smartphone group scored significantly higher on the SAS (80.7 vs. $46.5, p<.001)$, BIS (17.5 vs. $15.6, p=.013)$, and BDI (7.6 vs. $2.8, p=.002)$, and were more likely to use smartphone whenever possible (0.5 vs. $0.3, p=.027)$ than the problematic Internet user group. No significant differences existed between the two groups for BAS-F, BAI, CASS-S, AQ, or AX scores.

As shown in Table 3, the male $(n=295)$ and female $(n=260)$ students differed significantly with respect to 
Lee et al.

Table 2. Interclass comparison of the whole subjects $(N=555)$

\begin{tabular}{|c|c|c|c|c|c|c|c|}
\hline Variables & $\begin{array}{c}\text { Dual } \\
(n=275) \\
(49.5 \%)\end{array}$ & $\begin{array}{c}\text { Internet } \\
(n=43) \\
(7.7 \%)\end{array}$ & $\begin{array}{c}\text { Smartphone } \\
\left(\begin{array}{c}n=178) \\
(32.1 \%)\end{array}\right.\end{array}$ & $\begin{array}{l}\text { Healthy } \\
(n=59) \\
(10.6 \%)\end{array}$ & $\begin{array}{c}p \\
\text { value }\end{array}$ & $F$ & Post hoc \\
\hline \multicolumn{8}{|l|}{ Psychosocial measures } \\
\hline Internet Addiction Test & $42.8(12.0)$ & $35.8(9.8)$ & $23.8(2.8)$ & $21.1(1.2)$ & $<.001$ & 203.9 & $\mathrm{D}>\mathrm{I}>\mathrm{S} \fallingdotseq \mathrm{H}$ \\
\hline Smartphone Addiction Scale & $92.6(25.1)$ & $46.5(4.3)$ & $80.7(23.5)$ & $46.0(4.0)$ & $<.001$ & 108.4 & $\mathrm{D}>\mathrm{S}>\mathrm{I} \fallingdotseq \mathrm{H}$ \\
\hline BIS Scale & $17.8(3.6)$ & $15.6(3.5)$ & $17.5(3.7)$ & $15.7(4.1)$ & $<.001$ & 8.6 & $\mathrm{D} \fallingdotseq \mathrm{S}>\mathrm{H} \fallingdotseq \mathrm{I}$ \\
\hline Total BAS Scale & $30.1(8.1)$ & $26.5(10.3)$ & $27.5(9.1)$ & $24.6(9.7)$ & $<.001$ & 8.3 & $\mathrm{D}>\mathrm{S} \fallingdotseq \mathrm{H}$ \\
\hline BAS-R & $12.2(3.5)$ & $10.8(4.3)$ & $11.6(4.0)$ & $10.0(4.3)$ & $<.001$ & 6.3 & $\mathrm{D} \fallingdotseq \mathrm{S}>\mathrm{H}$ \\
\hline BAS-DG & $8.9(2.7)$ & $8.0(3.2)$ & $8.1(3.0)$ & $7.7(3.4)$ & .003 & 4.7 & $\mathrm{D}>\mathrm{S} \fallingdotseq \mathrm{H}$ \\
\hline BAS-F & $9.0(2.8)$ & $7.7(3.2)$ & $7.8(2.9)$ & $6.9(3.0)$ & $<.001$ & 11.3 & $\mathrm{D}>\mathrm{S} \fallingdotseq \mathrm{I} \fallingdotseq \mathrm{H}$ \\
\hline BDI & $8.9(8.2)$ & $2.8(3.6)$ & $7.6(7.6)$ & $4.2(6.9)$ & $<.001$ & 11.6 & $\mathrm{D} \fallingdotseq \mathrm{S}>\mathrm{H} \fallingdotseq \mathrm{I}$ \\
\hline BAI & $8.9(9.7)$ & $2.7(4.1)$ & $5.0(7.2)$ & $2.2(4.3)$ & $<.001$ & 18.2 & $\mathrm{D}>\mathrm{S} \fallingdotseq \mathrm{I} \fallingdotseq \mathrm{H}$ \\
\hline Barratt Impulsiveness Scale & $65.8(7.2)$ & $61.5(7.7)$ & $62.7(8.3)$ & $57.1(9.8)$ & $<.001$ & 21.4 & $\mathrm{D}>\mathrm{S} \fallingdotseq \mathrm{I}>\mathrm{H}$ \\
\hline CASS-S & $21.7(12.5)$ & $14.3(12.0)$ & $15.1(11.4)$ & $11.5(11.5)$ & $<.001$ & 18.7 & $\mathrm{D}>\mathrm{S} \fallingdotseq \mathrm{I} \fallingdotseq \mathrm{H}$ \\
\hline AQ & $70.4(19.7)$ & $52.4(16.3)$ & $60.1(18.9)$ & $48.0(11.7)$ & $<.001$ & 32.0 & $\mathrm{D}>\mathrm{S} \fallingdotseq \mathrm{I} \fallingdotseq \mathrm{H}, \mathrm{S}>\mathrm{H}$ \\
\hline $\mathrm{AX}$ & $56.2(10.3)$ & $49.5(12.9)$ & $51.8(11.1)$ & $47.1(12.1)$ & $<.001$ & 15.2 & $\mathrm{D}>\mathrm{S} \fallingdotseq \mathrm{I} \fallingdotseq \mathrm{H}, \mathrm{S}>\mathrm{H}$ \\
\hline \multicolumn{8}{|l|}{ Patterns survey } \\
\hline Gaming hours per play (A) & $1.8(1.7)$ & $2.3(1.6)$ & $0.9(1.0)$ & $0.6(0.8)$ & $<.001$ & 25.6 & $\mathrm{I} \fallingdotseq \mathrm{D}>\mathrm{S} \fallingdotseq \mathrm{H}$ \\
\hline Weekday daily gaming hours (A) & $1.3(1.5)$ & $2.0(1.9)$ & $0.6(1.0)$ & $0.4(0.9)$ & $<.001$ & 23.1 & $\mathrm{I}>\mathrm{D}>\mathrm{S} \fallingdotseq \mathrm{H}$ \\
\hline Weekend daily gaming hours (A) & $2.5(2.5)$ & $3.1(2.9)$ & $1.1(1.5)$ & $0.7(1.3)$ & $<.001$ & 25.2 & $\mathrm{I} \fallingdotseq \mathrm{D}>\mathrm{S} \fallingdotseq \mathrm{H}$ \\
\hline $\begin{array}{l}\text { Internet café as the main gaming } \\
\text { place }\end{array}$ & $0.2(0.4)$ & $0.1(0.3)$ & $0.1(0.3)$ & $0.2(0.4)$ & .018 & 10.1 & $\mathrm{D}>\mathrm{S}$ \\
\hline $\begin{array}{l}\text { Non-gaming Internet usage hours } \\
\text { per use (A) }\end{array}$ & $1.5(1.1)$ & $1.2(0.9)$ & $1.4(1.4)$ & $0.9(0.8)$ & .004 & 4.4 & $\mathrm{D} \fallingdotseq \mathrm{S}>\mathrm{H}$ \\
\hline $\begin{array}{l}\text { Weekday daily non-gaming } \\
\text { Internet hours (A) }\end{array}$ & $1.3(1.2)$ & $1.0(0.8)$ & $1.0(1.0)$ & $1.0(1.5)$ & .011 & 3.8 & $\mathrm{D}>\mathrm{S}$ \\
\hline $\begin{array}{l}\text { Weekend daily non-gaming } \\
\text { Internet hours (A) }\end{array}$ & $1.7(1.5)$ & $1.1(1.1)$ & $1.4(1.4)$ & $1.1(1.1)$ & .002 & 4.9 & $\mathrm{D}>\mathrm{H}$ \\
\hline Use Internet whenever possible & $0.2(0.4)$ & $0.2(0.4)$ & $0.1(0.3)$ & $0.1(0.3)$ & .002 & 14.5 & $\mathrm{D}>\mathrm{S} \fallingdotseq \mathrm{H}$ \\
\hline $\begin{array}{l}\text { Use smartphone whenever } \\
\text { possible }\end{array}$ & $0.5(0.5)$ & $0.3(0.4)$ & $0.5(0.5)$ & $0.2(0.4)$ & $<.001$ & 26.0 & $\mathrm{D} \fallingdotseq \mathrm{S}>\mathrm{H}, \mathrm{S}>\mathrm{I}$ \\
\hline
\end{tabular}

Note. A: average; AQ: Aggression Questionnaire; AX: Anger Expression Scale; BDI: Beck Depression Inventory; BAI: Beck Anxiety Inventory; BIS: Behavioral Inhibition System; BAS: Behavioral Activation System (R: reward responsiveness; DG: drive to pursuit goals; F: fun-seeking); CASS-S: Conners-Wells' Adolescent Self-Report Scale - short version; D: dual-problematic group; H: healthy group; I: Internet problem group; S: smartphone problem group.

numerous variables related to gaming, and in terms of Internet and smartphone usage. However, the demographic variables of age and household income did not demonstrate significant differences between the genders. The males displayed higher alcohol consumption experience than the females $(0.2 \%$ vs. $0.1 \%, p=.05)$, but smoking or psychiatric treatment histories did not differ by the gender. The females demonstrated more severe addiction than the males according to the SAS (85.9 vs. 74.9, respectively, $p<.001$ ), whereas males showed higher IAT scores than females $(36.4$ vs. 31.0, respectively, $p<.001)$. The average daily number of hours of use, of the non-gaming Internet and smartphones on weekdays and at the weekend, was higher in females. On the contrary, the males on average spent more time gaming on weekdays and at weekends. While the duration of Internet use per session was significantly longer in females, individual gaming sessions were significantly longer in males. Significant differences in psychosocial variables were also observed between genders. Scores on the psychometric instruments were generally higher in females, except for the CASS-S, BIS-11, and AQ (Table 3).
Reflecting the large gender differences, separate LCAs were performed for each gender. Unlike the four-class model for the whole group, a three-class model showed the best fit, according to the estimated BIC, for both the male and female students (Table 4).

However, the classification of the three subtypes differed by gender. The males were classified as (a) dual-problem users, (b) problematic Internet users, and (c) healthy users. For the females, however, a problematic smartphone group was identified instead of a problematic Internet group (Figure 2).

Interclass comparisons of the male subgroups showed similar results to those of the whole-group model. The dual-problem group displayed more severe psychopathology and addictive behaviors than the problematic Internet and the healthy groups (Table 5). The problematic Internet group showed significantly higher IAT scores (30.6 vs. 20.2, $p=.013)$, more hours of gaming per session ( $2.1 \mathrm{vs} .0 .8 \mathrm{hr}$, $p=.004)$, and more hours of gaming on weekdays (1.7 vs. $0.5 \mathrm{hr}, p=.026)$ and at the weekends $(2.7 \mathrm{vs} .1 .0 \mathrm{hr}, p=.025)$, on average, than the healthy group in post-hoc analyses. 
Table 3. Psychosocial and digital media-related variables of the participants

\begin{tabular}{|c|c|c|c|c|}
\hline \multirow[b]{2}{*}{ Characteristics } & \multicolumn{3}{|c|}{ Mean $(S D)$} & \multirow[b]{2}{*}{$p$ value } \\
\hline & Total & Male & Female & \\
\hline \multicolumn{5}{|l|}{ Demographic variables } \\
\hline Age & $13.9(0.3)$ & $13.9(0.3)$ & $13.9(0.4)$ & .214 \\
\hline Monthly household income & & & & .107 \\
\hline$<\$ 940$ & $22(5.7)$ & $11(5.0)$ & $11(6.8)$ & \\
\hline$\$ 940-1,880$ & $32(8.4)$ & $17(7.7)$ & $15(9.2)$ & \\
\hline$\$ 1,880-2,820$ & $57(14.9)$ & $37(16.8)$ & $20(12.3)$ & \\
\hline$\$ 2,820-3,760$ & $84(21.9)$ & $47(21.4)$ & $37(22.7)$ & \\
\hline$\$ 3,760-4,700$ & $53(13.8)$ & $24(10.9)$ & $29(17.8)$ & \\
\hline$\$ 4,700-5,640$ & $46(12.0)$ & $30(13.6)$ & $16(9.8)$ & \\
\hline$\$ 5,640-6,580$ & $33(8.6)$ & $15(6.8)$ & $18(11.0)$ & \\
\hline$\geq \$ 6,580$ & $56(14.6)$ & $39(17.7)$ & $17(10.4)$ & \\
\hline Alcohol $(+)^{\mathrm{a}}$ & $0.04(0.2)$ & $0.06(0.2)$ & $0.02(0.1)$ & .050 \\
\hline Smoking $(+)^{\mathrm{a}}$ & $0.02(0.1)$ & $0.02(0.1)$ & $0.01(0.1)$ & .614 \\
\hline Psychiatric treatment history $(+)^{\mathrm{a}}$ & $0.02(0.1)$ & $0.03(0.2)$ & $0.01(0.1)$ & .154 \\
\hline \multicolumn{5}{|l|}{ Psychosocial variables } \\
\hline Behavioral Inhibition System & $17.3(3.7)$ & $16.5(3.3)$ & $18.3(3.9)$ & $<.001$ \\
\hline Behavioral Activation System Scales & $28.4(9.0)$ & $27.5(9.5)$ & $29.4(8.3)$ & .017 \\
\hline Beck Depression Inventory & $7.5(7.8)$ & $5.7(6.5)$ & $9.5(8.7)$ & $<.001$ \\
\hline Beck Anxiety Inventory & $6.5(8.6)$ & $5.7(7.6)$ & $7.3(9.5)$ & .034 \\
\hline CASS-S & $17.9(12.6)$ & $18.3(13.2)$ & $17.4(11.9)$ & .422 \\
\hline Barratt Impulsiveness Scale & $63.6(8.3)$ & $63.6(7.9)$ & $63.5(8.8)$ & .910 \\
\hline Aggression Questionnaires & $59.0(20.0)$ & $57.5(21.0)$ & $60.6(18.6)$ & .070 \\
\hline State-Trait Anger Expression Inventory & $53.3(11.4)$ & $51.9(12.3)$ & $54.8(10.2)$ & .003 \\
\hline \multicolumn{5}{|l|}{ Digital media-related variables } \\
\hline Internet Addiction Test & $33.9(13.1)$ & $36.4(13.1)$ & $31.0(12.5)$ & $<.001$ \\
\hline Smartphone Addiction Scale & $80.1(28.0)$ & $74.9(24.2)$ & $85.9(30.7)$ & $<.001$ \\
\hline Weekday non-gaming Internet hours per day (A) & $1.1(1.1)$ & $1.0(0.9)$ & $1.3(1.4)$ & $<.001$ \\
\hline Weekend non-gaming Internet hours per day (A) & $1.5(1.4)$ & $1.2(1.1)$ & $1.9(1.7)$ & $<.001$ \\
\hline Non-gaming Internet usage hours per use & $1.4(1.2)$ & $1.2(1.2)$ & $1.6(1.2)$ & $<.001$ \\
\hline Weekday smartphone usage hours per day (A) & $2.9(2.5)$ & $2.5(2.0)$ & $3.4(2.8)$ & $<.001$ \\
\hline Weekend smartphone usage hours per day (A) & $3.8(3.0)$ & $3.1(2.5)$ & $4.6(3.3)$ & $<.001$ \\
\hline Weekday gaming hours per day (A) & $1.0(1.4)$ & $1.5(1.5)$ & $0.5(1.0)$ & $<.001$ \\
\hline Weekend gaming hours per day (A) & $1.9(2.3)$ & $2.8(2.2)$ & $0.8(1.8)$ & $<.001$ \\
\hline Gaming hours per play & $1.4(1.5)$ & $2.0(1.4)$ & $0.7(1.4)$ & $<.001$ \\
\hline
\end{tabular}

Note. A: average; CASS-S: Conners-Wells' Adolescent Self-Report Scale - short version; SD: standard deviation.

${ }^{\mathrm{a}}$ Frequency $(\%)$.

Table 4. Indicators of fit for models in the males and the females

\begin{tabular}{lccc}
\hline Model & BIC & AIC & BLRT $p$ value \\
\hline Males $(N=295)$ & & & \\
Two classes & 330.7431 & 293.8733 & .009 \\
Three classes & $\mathbf{2 6 1 . 9 2 2 1}$ & 206.6174 & .001 \\
Four classes & 268.2498 & 194.5103 & .004 \\
Females $(N=260)$ & & & \\
Two classes & 250.5642 & 214.9573 & .001 \\
Three classes & $\mathbf{2 3 0 . 1 6 2 5}$ & 176.7522 & .001 \\
Four classes & 240.8185 & 169.6049 & .030 \\
\hline
\end{tabular}

Note. Bold values represent the lowest BIC values and signify that the models composed by three class are most fit. AIC: Akaike information criterion; BIC: Bayesian information criterion; BLRT: Bootstrap Likelihood Ratio Test.

In the female LCA model, the dual-problem group demonstrated higher scores on psychosocial measurements and addictive behaviors than the problematic smartphone and the healthy groups (Table 6). The problematic smartphone group scored significantly higher on the SAS $(83.0$ vs. 47.0, $p<.001)$, BIS-11 (63.3 vs. 55.1, $p<.001)$, and AQ $(61.9$ vs. $48.9, p<.001)$ than the healthy group. Subjects in the problematic smartphone group were also more likely to respond positively to the question regarding the use of a smartphone whenever possible than the healthy group in the post-hoc analysis (0.6 vs. 0.1 , $p<.001)$.

\section{DISCUSSION}

In this study, we empirically showed that a four-class model most effectively categorized adolescents presenting with different degrees of problematic Internet and/or smartphone usage. The four classes generated by the LCA were as follows: (a) dual-problematic users, (b) problematic Internet 

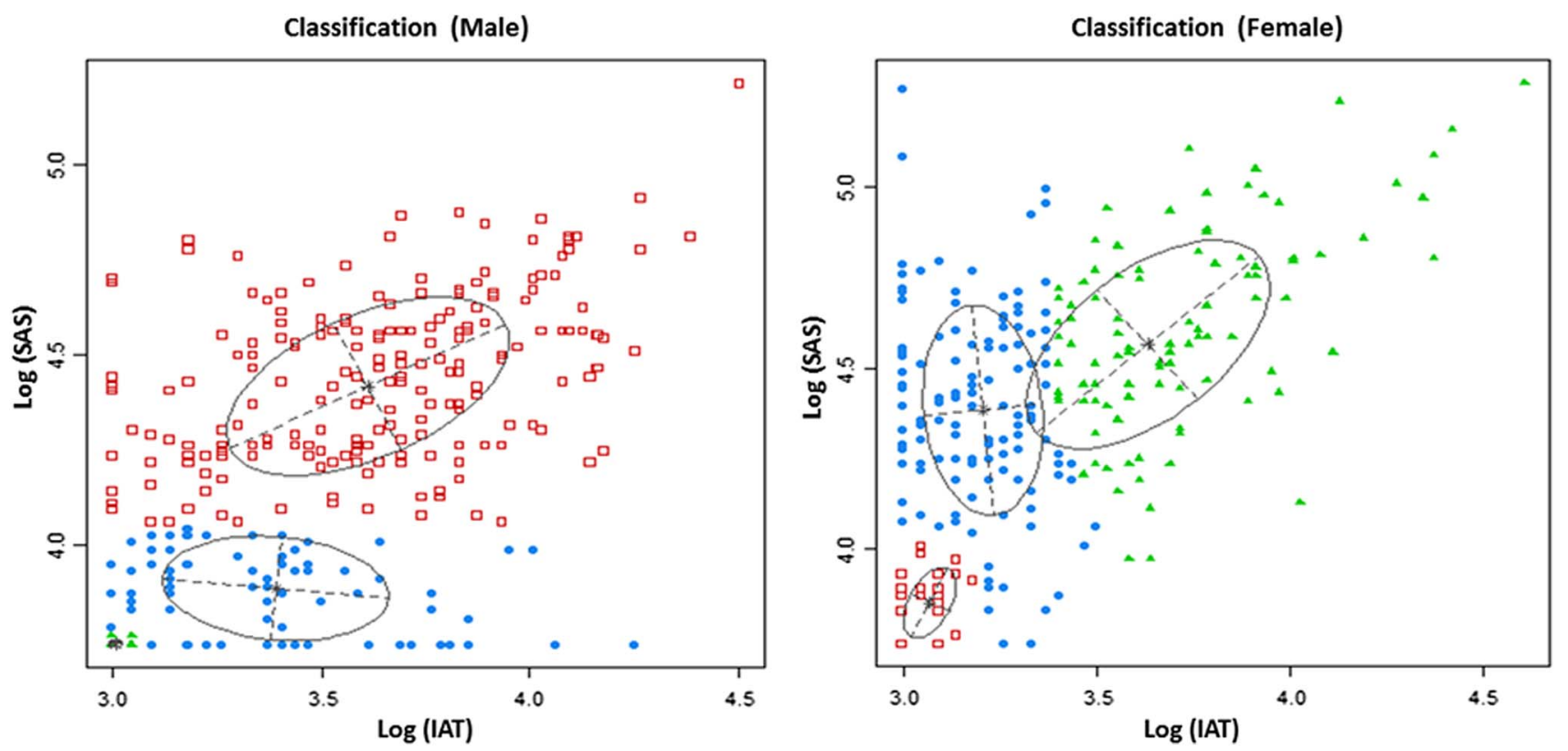

Figure 2. Latent class analysis of the males and the females. SAS: Smartphone Addiction Scale; IAT: Internet Addiction Test

Table 5. Interclass comparison of the males $(n=295)$

\begin{tabular}{|c|c|c|c|c|c|c|}
\hline Variables & $\begin{array}{c}\text { Dual } \\
(n=211)(71.5 \%)\end{array}$ & $\begin{array}{c}\text { Internet } \\
(n=71)(24.1 \%)\end{array}$ & $\begin{array}{c}\text { Healthy } \\
(n=13)(4.4 \%)\end{array}$ & $p$ value & $F$ & Post hoc \\
\hline \multicolumn{7}{|l|}{ Psychosocial measures } \\
\hline Internet Addiction Test & $39.4(13.0)$ & $30.6(10.0)$ & $20.2(0.4)$ & $<.001$ & 26.3 & $\mathrm{D}>\mathrm{I}>\mathrm{H}$ \\
\hline Smartphone Addiction Scale & $86.2(19.4)$ & $48.4(5.1)$ & $42.2(0.4)$ & $<.001$ & 163.8 & $\mathrm{D}>\mathrm{I} \fallingdotseq \mathrm{H}$ \\
\hline BIS Scale & $17.0(3.2)$ & $15.3(3.4)$ & $15.8(3.4)$ & .001 & 6.9 & $\mathrm{D}>\mathrm{I}$ \\
\hline Total BAS Scale & $28.6(9.0)$ & $25.0(9.5)$ & $23.9(12.6)$ & .008 & 4.9 & $\mathrm{D}>\mathrm{I}$ \\
\hline BAS-R & $11.6(3.7)$ & $10.4(4.3)$ & $9.1(4.7)$ & .011 & 4.5 & $\mathrm{D}>\mathrm{H}$ \\
\hline BAS-DG & $8.5(2.9)$ & $7.5(3.2)$ & $7.6(4.3)$ & .042 & 3.2 & $\mathrm{D}>\mathrm{I}$ \\
\hline BAS-F & $8.5(3.0)$ & $7.2(2.9)$ & $7.2(3.8)$ & .002 & 6.2 & $\mathrm{D}>\mathrm{I}$ \\
\hline BDI & $6.9(6.9)$ & $2.9(4.0)$ & $2.5(6.1)$ & $<.001$ & 12.1 & $\mathrm{D}>\mathrm{I} \fallingdotseq \mathrm{H}$ \\
\hline BAI & $7.1(8.2)$ & $2.7(4.8)$ & $0.9(2.3)$ & $<.001$ & 12.2 & $\mathrm{D}>\mathrm{I} \fallingdotseq \mathrm{H}$ \\
\hline Barratt Impulsiveness Scale & $64.9(7.3)$ & $60.0(8.3)$ & $62.7(10.0)$ & $<.001$ & 10.8 & $\mathrm{D}>\mathrm{I}$ \\
\hline CASS-S & $20.7(13.1)$ & $11.5(9.8)$ & $16.8(18.6)$ & $<.001$ & 13.7 & $\mathrm{D}>\mathrm{I}$ \\
\hline AQ & $66.2(21.1)$ & $52.3(14.8)$ & $48.9(15.3)$ & $<.001$ & 16.3 & $\mathrm{D}>\mathrm{I} \fallingdotseq \mathrm{H}$ \\
\hline $\mathrm{AX}$ & $53.3(11.6)$ & $48.7(12.6)$ & $46.9(15.8)$ & .008 & 5.0 & $\mathrm{D}>\mathrm{I}$ \\
\hline \multicolumn{7}{|l|}{ Patterns survey } \\
\hline Gaming hours per play (A) & $2.1(1.4)$ & $2.1(1.4)$ & $0.8(1.0)$ & .003 & 5.9 & $\mathrm{D} \fallingdotseq \mathrm{I}>\mathrm{H}$ \\
\hline Weekday daily gaming hours (A) & $1.5(1.4)$ & $1.7(1.9)$ & $0.5(0.9)$ & .034 & 3.4 & $\mathrm{I}>\mathrm{H}$ \\
\hline Weekend daily gaming hours (A) & $3.0(2.1)$ & $2.7(2.5)$ & $1.0(1.5)$ & .007 & 5.0 & $\mathrm{D} \fallingdotseq \mathrm{I}>\mathrm{H}$ \\
\hline Internet café as the main gaming place & $0.3(0.5)$ & $0.2(0.4)$ & $0.2(0.4)$ & .029 & 7.1 & $\mathrm{D}>\mathrm{I}$ \\
\hline $\begin{array}{l}\text { Non-gaming Internet usage hours per } \\
\text { use (A) }\end{array}$ & $1.2(1.3)$ & $1.0(0.9)$ & $0.7(0.6)$ & .158 & 1.9 & - \\
\hline $\begin{array}{l}\text { Weekday daily non-gaming Internet } \\
\text { hours (A) }\end{array}$ & $1.0(0.9)$ & $0.8(0.8)$ & $1.0(0.9)$ & .268 & 1.3 & - \\
\hline $\begin{array}{l}\text { Weekend daily non-gaming Internet } \\
\text { hours (A) }\end{array}$ & $1.3(1.2)$ & $0.9(1.0)$ & $1.4(1.2)$ & .032 & 3.5 & $\mathrm{D}>\mathrm{I}$ \\
\hline Use Internet whenever possible & $0.2(0.4)$ & $0.2(0.4)$ & $0.2(0.4)$ & .466 & 1.5 & - \\
\hline Use smartphone whenever possible & $0.4(0.5)$ & $0.3(0.5)$ & $0.2(0.4)$ & .017 & 8.1 & $\mathrm{D}>\mathrm{I}$ \\
\hline
\end{tabular}

Note. A: average; AQ: Aggression Questionnaire; AX: Anger Expression Scale; BDI: Beck Depression Inventory; BAI: Beck Anxiety Inventory; BIS: Behavioral Inhibition System; BAS: Behavioral Activation System (R: reward responsiveness; DG: drive to pursuit goals; F: fun-seeking); CASS-S: Conners-Wells' Adolescent Self-Report Scale - short version; D: dual-problematic group; H: healthy group; I: Internet problem group. 
Table 6. Interclass comparison of the females $(n=260)$

\begin{tabular}{|c|c|c|c|c|c|c|}
\hline Variables & $\begin{array}{c}\text { Dual } \\
(n=35) \\
(13.5 \%)\end{array}$ & $\begin{array}{c}\text { Smartphone } \\
(n=128) \\
(49.2 \%)\end{array}$ & $\begin{array}{l}\text { Healthy } \\
(n=97) \\
(37.3 \%)\end{array}$ & $p$ value & $F$ & Post hoc \\
\hline \multicolumn{7}{|l|}{ Psychosocial measures } \\
\hline Internet Addiction Test & $42.9(13.2)$ & $24.6(3.4)$ & $21.4(1.3)$ & $<.001$ & 156.6 & $\mathrm{D}>\mathrm{S} \fallingdotseq \mathrm{H}$ \\
\hline Smartphone Addiction Scale & $104.2(29.2)$ & $83.0(24.3)$ & $47.0(4.3)$ & $<.001$ & 70.3 & $\mathrm{D}>\mathrm{S}>\mathrm{H}$ \\
\hline BIS Scale & $19.2(3.9)$ & $17.9(3.7)$ & $17.2(4.4)$ & .014 & 4.3 & $\mathrm{D}>\mathrm{S} \fallingdotseq \mathrm{H}$ \\
\hline Total BAS Scale & $31.6(7.5)$ & $28.4(8.5)$ & $26.9(8.3)$ & .003 & 5.9 & $\mathrm{D}>\mathrm{S} \fallingdotseq \mathrm{H}$ \\
\hline BAS-R & $12.9(3.5)$ & $11.9(3.8)$ & $11.2(3.9)$ & .038 & 3.3 & - \\
\hline BAS-DG & $9.3(2.7)$ & $8.3(2.8)$ & $8.5(3.1)$ & .032 & 3.5 & $\mathrm{D}>\mathrm{S}$ \\
\hline BAS-F & $9.2(2.7)$ & $8.1(2.9)$ & $7.3(2.8)$ & .001 & 7.6 & $\mathrm{D}>\mathrm{S} \fallingdotseq \mathrm{H}$ \\
\hline BDI & $11.6(9.1)$ & $9.1(8.2)$ & $5.4(7.8)$ & .001 & 6.8 & $\mathrm{D}>\mathrm{H}$ \\
\hline BAI & $10.9(11.6)$ & $5.7(7.4)$ & $3.1(5.1)$ & $<.001$ & 13.5 & $\mathrm{D}>\mathrm{S} \fallingdotseq \mathrm{H}$ \\
\hline Barratt Impulsiveness & $66.8(7.2)$ & $63.3(8.2)$ & $55.1(9.7)$ & $<.001$ & 26.9 & $\mathrm{D}>\mathrm{S}>\mathrm{H}$ \\
\hline CASS-S & $22.0(11.9)$ & $15.8(11.4)$ & $10.8(8.5)$ & $<.001$ & 14.9 & $\mathrm{D}>\mathrm{S} \fallingdotseq \mathrm{H}$ \\
\hline AQ & $74.0(18.5)$ & $61.9(18.5)$ & $48.9(10.3)$ & $<.001$ & 27.1 & $\mathrm{D}>\mathrm{S}>\mathrm{H}$ \\
\hline $\mathrm{AX}$ & $57.8(9.7)$ & $53.5(10.1)$ & $51.0(9.7)$ & $<.001$ & 8.1 & $\mathrm{D}>\mathrm{S} \fallingdotseq \mathrm{H}$ \\
\hline \multicolumn{7}{|l|}{ Patterns survey } \\
\hline Gaming hours per play (A) & $1.0(1.9)$ & $0.5(1.0)$ & $0.3(0.7)$ & .008 & 4.9 & $\mathrm{D}>\mathrm{S} \fallingdotseq \mathrm{H}$ \\
\hline Weekday daily gaming hours (A) & $0.8(1.4)$ & $0.3(0.7)$ & $0.3(0.8)$ & .001 & 7.1 & $\mathrm{D}>\mathrm{S} \fallingdotseq \mathrm{H}$ \\
\hline Weekend daily gaming hours (A) & $1.3(2.4)$ & $0.6(1.2)$ & $0.4(1.0)$ & .006 & 5.2 & $\mathrm{D}>\mathrm{S} \fallingdotseq \mathrm{H}$ \\
\hline Internet café as the main gaming place & $0.0(0.2)$ & $0.0(0.2)$ & $0.1(0.2)$ & .594 & 1.0 & - \\
\hline $\begin{array}{l}\text { Non-gaming Internet usage hours } \\
\text { per use }(\mathrm{A})\end{array}$ & $2.0(1.3)$ & $1.4(1.0)$ & $1.1(0.9)$ & $<.001$ & 11.0 & $\mathrm{D}>\mathrm{S} \fallingdotseq \mathrm{H}$ \\
\hline $\begin{array}{l}\text { Weekday daily non-gaming Internet } \\
\text { hours (A) }\end{array}$ & $1.7(1.4)$ & $1.1(1.1)$ & $1.1(1.9)$ & .001 & 6.7 & $\mathrm{D}>\mathrm{S}$ \\
\hline $\begin{array}{l}\text { Weekend daily non-gaming Internet } \\
\text { hours (A) }\end{array}$ & $2.4(1.9)$ & $1.6(1.5)$ & $1.2(1.1)$ & $<.001$ & 10.9 & $\mathrm{D}>\mathrm{S} \fallingdotseq \mathrm{H}$ \\
\hline Use Internet whenever possible & $0.2(0.4)$ & $0.1(0.3)$ & $0.0(0.2)$ & .052 & 5.9 & - \\
\hline Use smartphone whenever possible & $0.5(0.5)$ & $0.6(0.5)$ & $0.1(0.3)$ & $<.001$ & 20.0 & $\mathrm{~S} \fallingdotseq \mathrm{D}>\mathrm{H}$ \\
\hline
\end{tabular}

Note. A: average; AQ: Aggression Questionnaire; AX: Anger Expression Scale; BDI: Beck Depression Inventory; BAI: Beck Anxiety Inventory; BIS: Behavioral Inhibition System; BAS: Behavioral Activation System (R: reward responsiveness; DG: drive to pursuit goals; F: fun-seeking); CASS-S: Conners-Wells' Adolescent Self-Report Scale - short version; D: dual-problematic group; H: healthy group; $\mathrm{S}$ : smartphone problem group.

users, (c) problematic smartphone users, and (d) "healthy" users. When compared with the healthy group, the dualproblem group demonstrated the most severe Internet- and smartphone-related problems. They also showed a poorer psychosocial profile in terms of anxiety, impulsivity, attention difficulties, and aggression.

The subclasses with problematic use in a single domain (Internet or smartphone) were generally intermediate between the dual-problem users and the healthy users in the psychosocial measures. However, despite their significantly lower IAT scores, the problematic Internet users showed a higher average number of hours spent gaming on weekdays than the dual-problem group.

When compared with the problematic smartphone group, the dual-problem group demonstrated significantly higher BAS-D and BAS-F scores, as well as anxiety, impulsivity, attention difficulty, and aggression. However, the sensitivity to punishment, such as BIS, BAS-R, and depression scores of the problematic smartphone group did not significantly differ from those of the dual-problem group.

Considering the gender differences in many psychosocial and digital media-related variables, LCA was separately performed for each gender. In contrast to the four-class model that showed the best fit for the whole group, three-class models provided the best fit for the male and female students. The males were categorized as (a) dual-problem users, (b) problematic Internet users, and (c) healthy users. The females were categorized as (a) dual-problem users, (b) problematic smartphone users, and (c) healthy users. Although both genders were best described by three-class models, the males included a subclass comprising only problematic Internet users, whereas the females included a subclass with only problematic smartphone use. These findings are consistent with a previous study that demonstrated similar variation in problematic digital media usage by gender (Mok et al., 2014).

A secondary objective of this study was to identify the underlying factors contributing to the gender differences. The females were more depressed, anxious, and sensitive to punishment and reward than the males. They also scored higher on the SAS and spent more time on smartphones than the males (Table 3). These findings are in line with the literature results. Mood and anxiety disorders, as well as problematic mobile phone use, have been reported to be higher among the females (Choi et al., 2015; Jiang \& Zhao, 2016; Kessler et al., 2012; Steel et al., 2014; Takao, Takahashi, \& Kitamura, 2009). 
In the female LCA model, the dual-problem group showed more severe psychopathology and digital media-related problems. Furthermore, the problematic smartphone group had significantly higher levels of impulsivity, aggression, and smartphone addiction, and used smartphones more frequently than the healthy users. Although it was previously reported that females are more likely to utilize mobile phones for socializing purposes (Bianchi \& Phillips, 2005), impulsivity and aggression, rather than sociability, may drive females to use their smartphones to a problematic degree. This is in line with a previous report, in which low self-control predicted problematic mobile phone use (Jiang \& Zhao, 2016).

However, the males in this study scored higher on the IAT and played games for longer periods. Although the males demonstrated a lower level of psychopathology, in general, they did not show significant differences from the females in terms of attention difficulty, impulsivity, or aggression (Table 3 ).

Closer inspection of the three male LCA clusters revealed that the dual-problem group had a higher degree of psychopathology, and more severe digital media-related problems, including Internet addiction, than the problematic Internet group. However, the two groups did not significantly differ in terms of the average number of hours of gaming per session, or the average number of hours spent gaming at the weekend. Thus, gaming appeared as the most important factor contributing to the relative preponderance of problematic Internet usage in the males. This view is in line with the literature, in which gaming has been reported as a major risk factor for Internet addiction (Kormas, Critselis, Janikian, Kafetzis, \& Tsitsika, 2011; Wu, Lee, Liao, \& Chang, 2015).

This study indicated that individuals with both problematic Internet and smartphone usage may experience higher difficulties from excessive use of new digital media platforms and more psychosocial distress. Considering that depression and anxiety have been related to problematic Internet use, gaming, and smartphone use (Elhai, Dvorak, Levine, \& Hall, 2017; Wei et al., 2012; Yen, Ko, Yen, Wu, \& Yang, 2007), a higher level of depression and anxiety among our subjects was not a surprise. However, such a dose-dependent relationship between more severe psychosocial problems and a greater number of digital mediarelated problems warrants additional clinical attention to people experiencing a greater number of digital-media use problems. In addition, further research should reveal whether more severe psychosocial problems lead to greater numbers of problematic digital media use, or the synergistic effect of 'dual-addictions' exert greater negative consequences on mental health.

This study demonstrated gender differences in the problematic use of digital media. Although these gender differences were partially explained by differences in digital media use patterns and psychosocial burden by gender, further studies should investigate whether such differences stem from biological or sociocultural differences, such as expected gender roles or neurodevelopment.

One of this study's interesting findings is the disproportionately overpresented dual-problem group in the males (71.5\%) compared with the female students (13.5\%). With increasing age, brain activity responsible for response inhibition was also reported to increase but with different pattern by gender (Rubia et al., 2013). Females displayed significantly higher activation in left superior and inferior frontal and striatal regions compared with males (Rubia et al., 2013). This finding hints that the females could have higher cognitive control than the males in the same age. Since higher impulsivity was observed for the dual problem group, the gender difference in brain maturation provides a plausible explanation for the relatively lower proportion of dual problems in the females than males (Ko, Yen, Chen, Chen, \& Yen, 2005; Mihara \& Higuchi, 2017).

The study results highlight that gaming is an important factor in males with Internet usage problems. It is also noteworthy that aggression and impulsivity were associated with problematic smartphone use among the females. Although aggression and impulsivity have been found to be associated with Internet addiction (Cao, Su, Liu, \& Gao, 2007; Ko, Yen, Liu, Huang, \& Yen, 2009; Koo \& Kwon, 2014; Yen et al., 2007), our findings contradict a report stating that females use mobile phones to socialize (Bianchi \& Phillips, 2005). Considering the higher level of fear among females (Tulviste, Kiive, Akkermann, \& Harro, 2015), smartphone use may allow them to express their anger or hostility in a way that they regard as being socially more acceptable. If this hypothesis is valid, a longitudinal study should examine whether such use would ultimately represent an adaptive or maladaptive coping strategy. However, reverse causality is also possible, with aggression being the result of excessive media usage. Nevertheless, aggression is an important factor to address in clinical assessments, because it may affect the persistence of problematic use (Ko, Yen, Yen, Lin, \& Yang, 2007).

This study had some limitations. First, the cross-sectional design allowed us to investigate only the current pattern of use and psychosocial variables of users, and their precise causal relationships could not be confirmed. For example, a problematic Internet user with high impulsivity could have become a pathological user due to his/her impulsivity, or vice versa. However, we cannot make inference on causality in this study; therefore, a longitudinal study is required. There were also limitations in terms of the lack of detailed information on the external environment of the subjects, such as parent-child and peer relationships. Furthermore, the psychosocial measurements relied on self-report measures with no objective assessments. However, because extensive psychosocial and digital media-related questionnaires were administered to the students, collecting too many details beyond the capacity that an adolescent could tolerate may actually undermine the overall study accuracy. Even though statistically higher scores in psychosocial measurements were displayed by the dual-problematic users, caution is required to interpret clinical significance. For instance, the mean values of BDI and BAI of this group were both 8.9 in the whole sample. Since the scores of $0-9$ are regarded as normal, those average scores are situated in subclinical level (Beck, Steer, \& Carbin, 1988; Julian, 2011). Sill, such subclinical distress by the dual excessive media usage may act as a background predisposing vulnerability and grant a clinical significance when the individual encounters other stressors in life. Considering that the study participants were not clinical sample, further studies in clinical populations are also required to ascertain the full clinical value of these findings. 
In conclusion, this study revealed different patterns of problematic use of new digital media platforms among adolescents by gender. Four user subgroups were identified among the whole population. Although having dual-problem and healthy groups in common, distinct classes of problematic use, i.e., problematic Internet users versus problematic smartphone users, were identified in the males and the females, respectively, in the gender-stratified LCA. Gaming was associated with problematic Internet usage in males. On the contrary, higher levels of impulsivity and aggression were observed in the female problematic smartphone users; this group may use their smartphones as a means of releasing their impulsivity or frustration. Future research is required to confirm this hypothesis and to test whether such actions are useful for alleviating psychosocial burden or worsens it. Regardless of gender, in general, the dual-problem group demonstrated the most severe psychosocial and digital media-related problems. Thus, evaluating whether there are multiple types of addictive behavior in the context of digital media use could help us acquire a clearer clinical picture, similar to evaluating additional substance misuse behaviors among patients with a substance-use disorder.

Funding sources: This study was supported by a grant of the Korean Mental Health Technology R\&D Project, Ministry of Health and Welfare, Republic of Korea (HM14C2603), and the National Research Foundation of Korea (2014M3C7A1062894).

Authors' contribution: S-YL led the drafting of the manuscript and DL, CRN, SP, and J-GK also took part in drafting. DL, DYK, and YL conducted the analyses. Y-SK and J-SC developed the concept and supervised. DJK reviewed the scientific and further developed the concept. All authors contributed to the editorial comments.

Conflict of interest: None.

\section{REFERENCES}

Achab, S., Nicolier, M., Mauny, F., Monnin, J., Trojak, B., Vandel, P., Sechter, D., Gorwood, P., \& Haffen, E. (2011). Massively multiplayer online role-playing games: Comparing characteristics of addict vs non-addict online recruited gamers in a French adult population. BMC Psychiatry, 11(1), 144. doi:10.1186/1471-244X-11-144

Ayers, J. W., Leas, E. C., Dredze, M., Allem, J., Grabowski, J. G., \& Hill, L. (2016). Pokémon go - A new distraction for drivers and pedestrians. JAMA Internal Medicine, 176(12), 1865-1866. doi:10.1001/jamainternmed.2016.6274

Bahn, G. H., Shin, M. S., Cho, S. C., \& Hong, K. E. (2001). A preliminary study for the development of the assessment scale for ADHD in adolescents: Reliability and validity for CASS(S). Korean Journal of Child \& Adolescent Psychiatry, 12(2), 218-224.

Beck, A. T., Epstein, N., Brown, G., \& Steer, R. A. (1988). An inventory for measuring clinical anxiety: Psychometric properties. Journal of Consulting and Clinical Psychology, 56(6), 893-897. doi:10.1037//0022-006X.56.6.893

Beck, A. T., Steer, R. A., \& Carbin, M. G. (1988). Psychometric properties of the Beck Depression Inventory: Twenty-five years of evaluation. Clinical Psychology Review, 8(1), 77-100. doi:10.1016/0272-7358(88)90050-5

Beck, A. T., Ward, C. H., Mendelson, M., Mock, J., \& Erbaugh, J. (1961). An inventory for measuring depression. Archives of General Psychiatry, 4, 561-571. doi:10.1001/archpsyc.1961. 01710120031004

Bianchi, A., \& Phillips, J. G. (2005). Psychological predictors of problem mobile phone use. CyberPsychology \& Behavior, 8(1), 39-51. doi:10.1089/cpb.2005.8.39

Borsari, B., Zamboanga, B. L., Correia, C., Olthuis, J. V., Van Tyne, K., Zadworny, Z., Grossbard, J. R., \& Horton, N. J. (2013). Characterizing high school students who play drinking games using latent class analysis. Addictive Behaviors, 38(10), 2532-2540. doi:10.1016/j.addbeh. 2013.04.009

Buss, A. H., \& Perry, M. (1992). The Aggression Questionnaire. Journal of Personality and Social Psychology, 63(3), 452-459. doi:10.1037/0022-3514.63.3.452

Cao, F., Su, L., Liu, T., \& Gao, X. (2007). The relationship between impulsivity and Internet addiction in a sample of Chinese adolescents. European Psychiatry, 22(7), 466-471. doi:10.1016/j.eurpsy.2007.05.004

Carras, M. C., Van Rooij, A. J., Van de Mheen, D., Musci, R., Xue, Q. L., \& Mendelson, T. (2017). Video gaming in a hyperconnected world: A cross-sectional study of heavy gaming, problematic gaming symptoms, and online socializing in adolescents. Computers in Human Behavior, 68, 472-479. doi:10.1016/j.chb.2016.11.060

Carver, C. S., \& White, T. L. (1994). Behavioral inhibition, behavioral activation, and affective responses to impending reward and punishment: The BIS/BAS Scales. Journal of Personality and Social Psychology, 67(2), 319-333. doi:10.1037/0022-3514.67.2.319

Choi, S. W., Kim, D. J., Choi, J. S., Ahn, H., Choi, E. J., Song, W. Y., Kim, S., \& Youn, H. (2015). Comparison of risk and protective factors associated with smartphone addiction and Internet addiction. Journal of Behavioral Addictions, 4(4), 308-314. doi:10.1556/2006.4.2015.043

Conners, C. (1997). Conners' Rating Scales - Revised technical manual. Toronto, ON: Multi-Health Systems.

Dantlgraber, M., Wetzel, E., Schutzenberger, P., Stieger, S., \& Reips, U. D. (2016). Simple construct evaluation with latent class analysis: An investigation of Facebook addiction and the development of a short form of the Facebook Addiction Test (F-AT). Behavior Research Methods, 48(3), 869-879. doi:10.3758/s13428-016-0716-2

Elhai, J. D., Dvorak, R. D., Levine, J. C., \& Hall, B. J. (2017). Problematic smartphone use: A conceptual overview and systematic review of relations with anxiety and depression psychopathology. Journal of Affective Disorders, 207, 251-259. doi:10.1016/j.jad.2016.08.030

Eurostat. (2017). Digital economy and society statistics Households and individuals. Retrieved from http://ec.europa. eu/eurostat/statistics-explained/index.php/Digital_economy_ and_society_statistics_-_households_and_individuals

Frangos, K., Frangos, C., \& Sotiropoulos, I. (2012). A meta-analysis of the reliabilty of Young's Internet Addiction Test 
(Vol. 1). London, UK: Proceedings of the World Congress on Engineering.

Galvan, A., Hare, T., Voss, H., Glover, G., \& Casey, B. J. (2007). Risk-taking and the adolescent brain: Who is at risk? Developmental Science, 10(2), F8-F14. doi:10.1111/j.14677687.2006.00579.x

Gentile, D. A., Choo, H., Liau, A., Sim, T., Li, D., Fung, D., \& Khoo, A. (2011). Pathological video game use among youths: A two-year longitudinal study. Pediatrics, 127(2), e319-e329. doi:10.1542/peds.2010-1353

Gray, J. A. (1990). Brain systems that mediate both emotion and cognition. Cognition \& Emotion, 4(3), 269-288. doi:10.1080/ 02699939008410799

Hagenaars, J. A., \& McCutcheon, A. L. (2002). Applied latent class analysis. Cambridge, UK: Cambridge University Press.

Hahn, D. W., Lee, C. H., \& Chon, K. K. (1998). Korean adaptation of the State-Trait Anger Expression Inventory (STAXI-K): The case of college students. Korean Journal of Health Psychology, 3(1), 18-32.

Hull, J. G., Draghici, A. M., \& Sargent, J. D. (2012). A longitudinal study of risk-glorifying video games and reckless driving. Psychology of Popular Media Culture, 1(4), 244-253. doi: $10.1037 / \mathrm{a} 0029510$

Jiang, Z., \& Zhao, X. (2016). Self-control and problematic mobile phone use in Chinese college students: The mediating role of mobile phone use patterns. BMC Psychiatry, 16(1), 416. doi:10.1186/s12888-016-1131-z

Julian, L. J. (2011). Measures of anxiety: State-Trait Anxiety Inventory (STAI), Beck Anxiety Inventory (BAI), and Hospital Anxiety and Depression Scale-Anxiety (HADS-A). Arthritis Care \& Research, 63(S11), S467-S472. doi:10.1002/ acr.20561

Kessler, R. C., Avenevoli, S., Costello, E. J., Georgiades, K., Green, J. G., Gruber, M. J., He, J. P., Koretz, D., McLaughlin, K. A., Petukhova, M., Sampson, N. A., Zaslavsky, A. M., \& Merikangas, K. R. (2012). Prevalence, persistence, and sociodemographic correlates of DSM-IV disorders in the National Comorbidity Survey Replication Adolescent Supplement. Archives of General Psychiatry, 69(4), 372380. doi:10.1001/archgenpsychiatry.2011.160

Kim, K., Ryu, E., Chon, M.-Y., Yeun, E.-J., Choi, S.-Y., Seo, J.-S., \& Nam, B.-W. (2006). Internet addiction in Korean adolescents and its relation to depression and suicidal ideation: A questionnaire survey. International Journal of Nursing Studies, 43(2), 185-192. doi:10.1016/j.ijnurstu.2005.02.005

Kim, S. H., Jung, S., Park, K., Jaekal, E., Lee, S. H., Choi, Y., Lee, W. H., \& Choi, K. H. (2016). Development of the Korean screening tool for anxiety disorders: Review of current anxiety scales and development of preliminary item pools. Korean Journal of Clinical Psychology, 35(3), 630-644. doi:10.15842/ kjcp.2016.35.3.004

Kiraly, O., Sleczka, P., Pontes, H. M., Urban, R., Griffiths, M. D., \& Demetrovics, Z. (2017). Validation of the Ten-Item Internet Gaming Disorder Test (IGDT-10) and evaluation of the nine DSM-5 Internet gaming disorder criteria. Addictive Behaviors, 64, 253-260. doi:10.1016/j.addbeh.2015.11.005

Ko, C. H., Yen, J. Y., Chen, C. C., Chen, S. H., \& Yen, C. F. (2005). Gender differences and related factors affecting online gaming addiction among Taiwanese adolescents. The Journal of Nervous and Mental Disorders, 193(4), 273-277. doi:10.1097/01.nmd.0000158373.85150.57
Ko, C.-H., Yen, J.-Y., Liu, S.-C., Huang, C.-F., \& Yen, C.-F. (2009). The associations between aggressive behaviors and Internet addiction and online activities in adolescents. Journal of Adolescent Health, 44(6), 598-605. doi:10.1016/j. jadohealth.2008.11.011

Ko, C. H., Yen, J. Y., Yen, C. F., Lin, H. C., \& Yang, M. J. (2007). Factors predictive for incidence and remission of Internet addiction in young adolescents: A prospective study. Cyber Psychology \& Behavior, 10(4), 545-551. doi:10.1089/ cpb.2007.9992

Koo, H. J., \& Kwon, J. H. (2014). Risk and protective factors of Internet addiction: A meta-analysis of empirical studies in Korea. Yonsei Medical Journal, 55(6), 1691-1711. doi:10.3349/ymj.2014.55.6.1691

Kormas, G., Critselis, E., Janikian, M., Kafetzis, D., \& Tsitsika, A. (2011). Risk factors and psychosocial characteristics of potential problematic and problematic Internet use among adolescents: A cross-sectional study. BMC Public Health, 11(1), 595. doi:10.1186/1471-2458-11-595

Kwon, M., Lee, J. Y., Won, W. Y., Park, J. W., Min, J. A., Hahn, C., Gu, X., Choi, J. H., \& Kim, D. J. (2013). Development and validation of a Smartphone Addiction Scale (SAS). PLoS One, 8(2), e56936. doi:10.1371/journal.pone.0056936

Lee, S.-R., Lee, W.-H., Park, J.-S., Kim, S.-M., Kim, J.-W., \& Shim, J.-H. (2012). The study on reliability and validity of Korean version of the Barratt Impulsiveness Scale-11-revised in nonclinical adult subjects. Journal of Korean Neuropsychiatric Association, 51(6), 378-386. doi:10.4306/jknpa.2012.51.6.378

Lemmens, J. S., Valkenburg, P. M., \& Gentile, D. A. (2015). The Internet Gaming Disorder Scale. Psychological Assessment, 27(2), 567-582. doi:10.1037/pas0000062

Lennon, A., Oviedo-Trespalacios, O., \& Matthews, S. (2017). Pedestrian self-reported use of smart phones: Positive attitudes and high exposure influence intentions to cross the road while distracted. Accident; Analysis and Prevention, 98, 338-347. doi:10.1016/j.aap.2016.10.028

Messias, E., Castro, J., Saini, A., Usman, M., \& Peeples, D. (2011). Sadness, suicide, and their association with video game and Internet overuse among teens: Results from the youth risk behavior survey 2007 and 2009. Suicide \& Life-Threatening Behavior, 41(3), 307-315. doi:10.1111/j.1943-278X.2011. 00030.x

Mihara, S., \& Higuchi, S. (2017). Cross-sectional and longitudinal epidemiological studies of Internet gaming disorder: A systematic review of the literature. Psychiatry and Clinical Neurosciences, 71(7), 425-444. doi:10.1111/pcn.12532

Rhee, M. K., Lee, Y. H., Park, S. H., Sohn, C. H., Chung, Y. C., Hong, S. K., Son, C. H., Jeong, Y. J., Chang, P., \& Yoon, A. R. (1995). A standardization study of Beck Depression Inventory 1 - Korean Version (K-BDI): Reliability and factor analysis. The Korean Journal of Psychopathology, 4(1), 77-95.

Mok, J. Y., Choi, S. W., Kim, D. J., Choi, J. S., Lee, J., Ahn, H., Choi, E. J., \& Song, W. Y. (2014). Latent class analysis on Internet and smartphone addiction in college students. Neuropsychiatric Disease and Treatment, 10, 817-828. doi:10. 2147/ndt.s59293

Nylund, K. L., Asparouhov, T., \& Muthén, B. O. (2007). Deciding on the number of classes in latent class analysis and growth mixture modeling: A Monte Carlo simulation study. Structural Equation Modeling, 14(4), 535-569. doi:10.1080/10705510 701575396 
Patton, J. H., Stanford, M. S., \& Barratt, E. S. (1995). Factor structure of the Barratt Impulsiveness Scale. Journal of Clinical Psychology, 51(6), 768-774. doi:10.1002/1097-4679 (199511)51:6\%3C768::AID-JCLP2270510607\%3E3.0.CO;2-1

R Development Core Team. (2011). $R$ : A language and environment for statistical computing. Vienna, Austria: $\mathrm{R}$ Foundation for Statistical Computing. Retrieved from http://www.R-project.org

Rubia, K., Lim, L., Ecker, C., Halari, R., Giampietro, V., Simmons, A., Brammer, M., \& Smith, A. (2013). Effects of age and gender on neural networks of motor response inhibition: From adolescence to mid-adulthood. Neuroimage, 83, 690-703. doi:10.1016/j.neuroimage.2013. 06.078

Rumpf, H. J., Vermulst, A. A., Bischof, A., Kastirke, N., Gurtler, D., Bischof, G., Meerkerk, G. J., John, U., \& Meyer, C. (2014). Occurrence of Internet addiction in a general population sample: A latent class analysis. European Addiction Research, 20(4), 159-166. doi:10.1159/000354321

Spielberger, C. D., Johnson, E. H., Russell, S. F., Crane, R. J., Jacobs, G. A., \& Worden, T. J. (1985). The experience and expression of anger: Construction and validation of an Anger Expression Scale. In M. A. Chesney, \& R. H. Rosenman (Eds.), Anger and hostility in cardiovascular and behavioral disorders. New York, NY: Hemisphere/McGraw-Hills.

Steel, Z., Marnane, C., Iranpour, C., Chey, T., Jackson, J. W., Patel, V., \& Silove, D. (2014). The global prevalence of common mental disorders: A systematic review and metaanalysis 1980-2013. International Journal of Epidemiology, 43(2), 476-493. doi:10.1093/ije/dyu038

Takao, M., Takahashi, S., \& Kitamura, M. (2009). Addictive personality and problematic mobile phone use. Cyber Psychology \& Behavior, 12(5), 501-507. doi:10.1089/ cpb.2009.0022
Tulviste, T., Kiive, E., Akkermann, K., \& Harro, J. (2015). Fears in the general population: More frequent in females and associated with the serotonin transporter promoter polymorphism and perceived relationship with mothers. Journal of Child Neurology, 30(11), 1459-1465. doi:10.1177/0883073815570151

Vandewater, E. A., Shim, M.-S., \& Caplovitz, A. G. (2004). Linking obesity and activity level with children's television and video game use. Journal of Adolescence, 27(1), 71-85. doi:10.1016/j.adolescence.2003.10.003

Wei, H. T., Chen, M. H., Huang, P. C., \& Bai, Y. M. (2012). The association between online gaming, social phobia, and depression: An Internet survey. BMC Psychiatry, 12(1), 92. doi:10. 1186/1471-244X-12-92

Weinstein, A., \& Weizman, A. (2012). Emerging association between addictive gaming and attention-deficit/hyperactivity disorder. Current Psychiatry Reports, 14(5), 590-597. doi:10. 1007/s11920-012-0311-x

Wu, C. Y., Lee, M. B., Liao, S. C., \& Chang, L. R. (2015). Risk factors of Internet addiction among Internet users: An online questionnaire survey. PLoS One, 10(10), e 0137506. doi:10. 1371/journal.pone.0137506

Wu, X., Tao, S., Zhang, Y., Zhang, S., \& Tao, F. (2015). Low physical activity and high screen time can increase the risks of mental health problems and poor sleep quality among Chinese college students. PLoS One, 10(3), e0119607. doi:10.1371/ journal.pone. 0119607

Yen, J. Y., Ko, C. H., Yen, C. F., Wu, H. Y., \& Yang, M. J. (2007). The comorbid psychiatric symptoms of Internet addiction: Attention deficit and hyperactivity disorder (ADHD), depression, social phobia, and hostility. Journal of Adolescent Health, 41(1), 93-98. doi:10.1016/j.jadohealth.2007.02.002

Young, K. S. (1999). The research and controversy surrounding Internet addiction. CyberPsychology \& Behavior, 2(5), 381-383. doi:10.1089/cpb.1999.2.381 